\title{
Proposed alternative terminology and subclassification of so called "dysplastic naevi"
}

\author{
MORAG M SEYWRIGHT, ${ }^{*}$ VALERIE R DOHERTY, $\dagger$ RONA M MacKIE† \\ From the Departments of + Dermatology and ${ }^{*}$ Pathology, Western Infirmary, University of Glasgow
}

SUMMARY The term "dysplastic" melanocytic naevus has recently been used to describe pigmented naevi with unusual histological and clinical features. There is currently no clear clinical or pathological definition of the term, and this has led to a lack of comparability of material described in reports on these lesions.

As a result of careful histological study and a clinicopathological correlation of 100 naevi, we suggest that three distinct groups of histopathological features distinguish so called dysplastic naevi from banal melanocytic naevi. These are architectural atypia, cytological atypia, and a host response. Description of each of these features in routine reports and in published series in place of the loose use of the term "dysplastic" would enable comparisons to be made between series of melanocytic lesions reported from different centres.

In the course of this study we observed a considerably increased incidence of naevus type giant cells in the dermal portion of the atypical naevi. These giant cells should not be confused with possibly premalignant cytological atypia.

There is both confusion and controversy over the accurate histological definition of a "dysplastic" naevus. This paper concentrates on clarifying this and is not concerned with the related problem of the accurate clinical definition of dysplastic naevus syndrome.

Two main histological features have been reported in association with these naevi ${ }^{1-3}$ : lentiginous melanocytic hyperplasia (our suggested terminology for this abnormal growth pattern is architectural atypia); and melanocytic cytological atypia. Clark et al considered that a combination of architectural atypia and cytological atypia constitutes melanocytic dysplasia, and that the diagnosis cannot be made in the absence of cytological atypia. ${ }^{2}$ In contrast, at a National Institutes of Health Consensus Development Conference it was concluded that cytological atypia, although often present, was not essential for the diagnosis of a dysplastic naevus. ${ }^{4}$ This viewpoint has recently been supported by Ackerman. ${ }^{5}$

The continuing controversy over this crucial point, which was discussed at length but remained unresolved at the recent First International Conference on Skin Melanoma (Venice, May 1985; proceedings

Accepted for publication 23 October 1985 in press) has created difficulties for the diagnostic pathologist in deciding on the criteria to be satisfied before a melanocytic naevus is reported as dysplastic. We therefore examined 100 naevi from 60 patients with the following objectives:

1 To determine in this series the incidence of naevi showing architectural atypia and of naevi showing cytological atypia and to ascertain whether architectural and cytological atypia always coexist.

2 To determine the incidence in this series of features indicative of a host response to the naevusnamely, a dermal lymphocytic infiltrate and fibroplasia.

3 To suggest a simplified repeatable method of histological reporting of atypical naevi that could be easily adopted by all pathologists.

\section{Material and methods}

Sections stained by haematoxylin and eosin of 100 consecutive melanocytic naevi from 60 patients selected from the routine dermatopathology files in 1984 and early 1985 were examined by two independent observers who did not know the clinical details in each case at the time of microscopic examination. The naevi were assessed for the histological features described by Elder et $a l^{1}$ and Clark et al. ${ }^{2}$ 


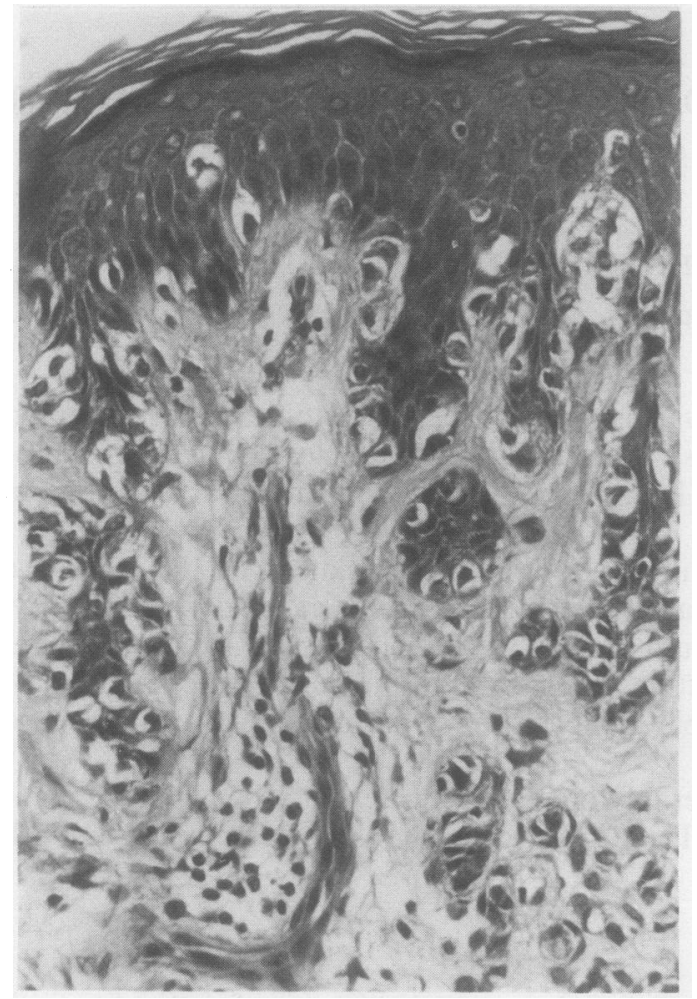

Fig. 1 Architectural atypia in melanocytic naevus. Note irregularly distributed increased numbers of cytologically normal melanocytes. Rete peg elongation is well seen at each side of field. A mild lymphocytic host response is present in dermis.

\section{ARCHITECTURAL ATY PIA (LMH)}

This is characterised by hyperplasia of irregularly orientated basally situated melanocytes with elongation of rete ridges (Fig. 1). There may be some aggregation of melanocytes into nests, with a tendency to lateral extension of nests, which produce horizontally orientated bridges between adjacent rete ridges (Fig. 2).

CYTOLOGICAL ATYPIA (FIG. 3)

This is characterised by nuclear pleomorphism and hyperchromatism, but only occasional mitotic figures. Two main forms have been described. The first cell type has a large hyperchromatic nucleus and scanty cytoplasm showing artefactual shrinkage. The second "epithelioid" cell type has a less hyperchromatic nucleus and more abundant cytoplasm containing fine melanin pigment.

In addition to architectural and cytological atypia, two other features, fibroplasia and a dermal lymphoid infiltrate, are associated with naevi described as dysplastic. Both are thought to represent a host response, and the presence of both of these features, either singly or in combination, was therefore noted in this series.

Fibroplasia may be concentric or lamellar. Lamellar fibroplasia consists of horizontally or vertically distributed strands of thickened collagen in the papillary dermis (Fig. 4). Concentric fibroplasia consists of a broad band of acellular collagen that follows the margins of the rete ridges just beneath the dermoepidermal junction (Figs. 5a and b).

In the course of examining the sections for the presence of atypia we observed that a high proportion of sections from patients with architectural and combined cytological and architectural atypia showed naevus type giant cell formation in the dermal component of the naevus (Fig. 6a). On superficial examination these might be confused with possibly premalignant cytological atypia, in which large cells with a high nuclear cytoplasmic ratio, some of which are multinucleate, are seen (Fig. 6b). These are located principally in the region of the dermoepidermal junction.

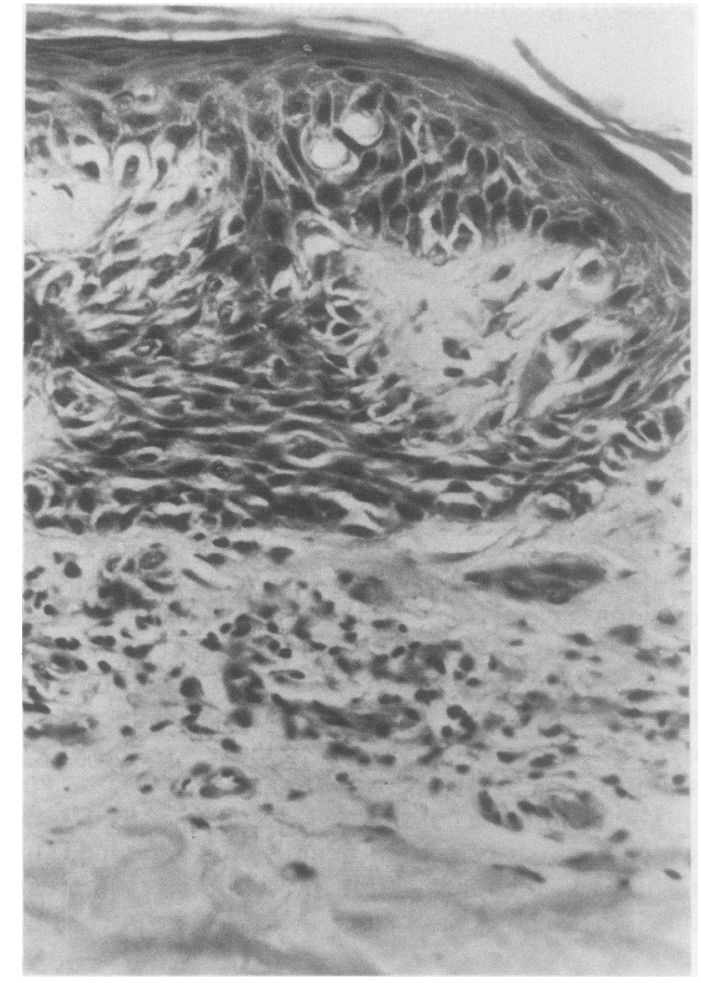

Fig. 2 Architectural atypia. Horizontal fusion of nests of cytologically normal melanocytes can be seen. 


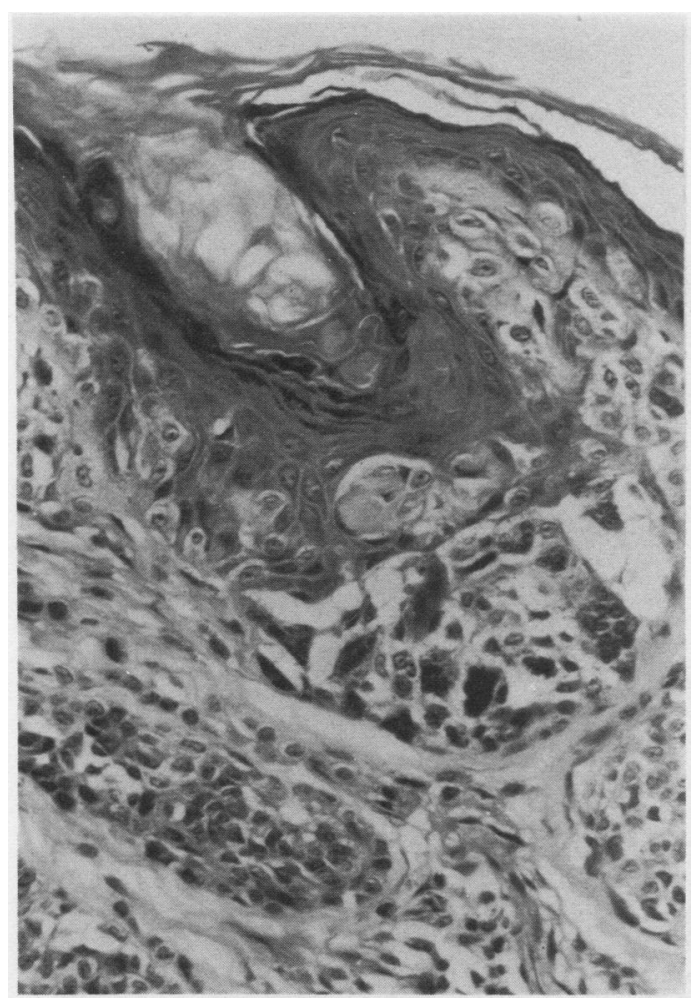

Fig. 3 Cytological melanocytic atypia. Obvious abnormality of the nuclear:cytoplasmic ratio of melanocytes at dermoepidermal junction.

\section{Results}

Based on the presence or absence of architectural and cytological atypia, the 100 melanocytic naevi in this series were divided into three categories:

1 Junctional, compound, or intradermal naevi showing no architectural or cytological atypia

Sixty two naevi examined were of this type. Thirteen of these displayed a dermal host response, 11 with a dermal lymphoid infiltrate alone, and two with fibroplasia. No naevus in this group showed both a lymphoid infiltrate and fibroplasia.

2 Junctional or compound naevi showing architectural atypia but no cytological atypia

Eight naevi were of this type. Six of these displayed a dermal host response, one with a lymphoid infiltrate alone, four with fibroplasia alone, and one with both fibroplasia and a lymphoid infiltrate.

3 Junctional or compound naevi showing both architectural atypia and cytological atypia

Thirty naevi were of this type. Twenty six of these displayed a dermal host response, seven with a lym-
Table 1 Presence of giant cells in routinely cut sections

\begin{tabular}{lcc}
\hline Type of giant cells & $\begin{array}{l}\text { Banal } \\
\text { naevi }\end{array}$ & $\begin{array}{l}\text { Atypical } \\
\text { naevi }\end{array}$ \\
\hline Banal naevus type giant cells present & 17 & 27 \\
$\begin{array}{l}\text { Cytologically atypical basal layer giant cells } \\
\text { present }\end{array}$ & 0 & $3^{*}$ \\
Giant cells absent & 45 & 8 \\
\hline
\end{tabular}

*All of these three specimens are from patients with both architectural and cytological atypia, one of whom has an additional personal history of melanoma.

phoid infiltrate alone, four with only fibroplasia, and 15 with both a lymphoid infiltrate and fibroplasia.

There were no naevi in this series showing cytological atypia without associated architectural atypia.

Naevus type giant cells were seen in 17 of $62(27 \%)$ of the simple naevi and in 27 of $38(71 \%)$ of naevi showing either architectural atypia alone or architectural and cytological atypia. The difference between these two incidence figures was highly significant $\left(\chi^{2}\right.$ $=17.2 ; \mathrm{p}<0.001)($ Table 1$)$.

A detailed clinical analysis of the patients included in this study will be the subject of a separate clinical report. Tables 2 and 3 give a brief analysis of the

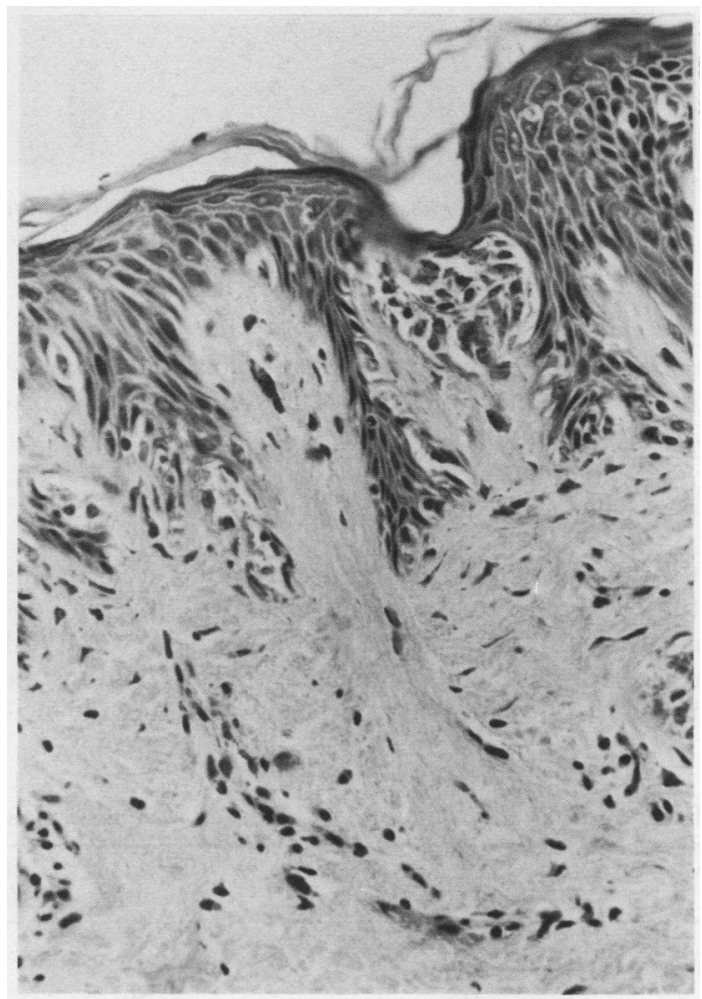

Fig. 4 Lamellar fibroplasia. Note horizontally and vertically aligned strands of coarse collagen in papillary dermis. 


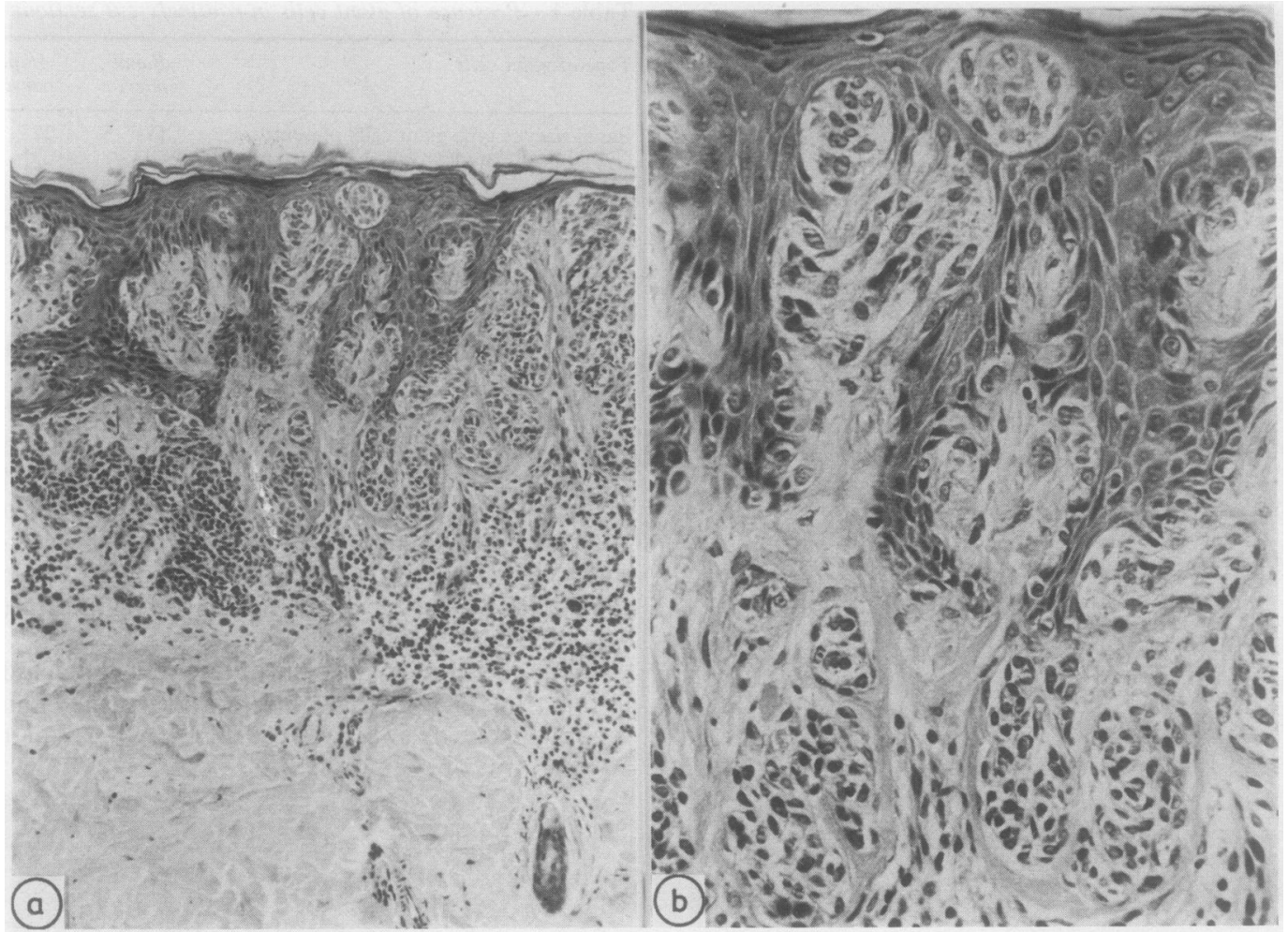

Fig. 5 (a) Dermal host response. Naevus showing architectural atypia and both concentric fibroplasia and underlying lymphocytic infiltrate. (b) Higher power view of 5a showing dermal fibroplasia in greater detail. Note condensation of dermal collagen around naevus cells.

association between histological atypia and the presence of multiple moles and a personal or family history of melanoma.

\section{Discussion}

It should be emphasised that the sample used in this study was a selected population as the University department of dermatology runs a specialised referral service for cutaneous pigmented lesions. The results should therefore not be regarded as reflecting the inci- dence of atypical naevi in the Scottish population as a whole and should not be quoted in epidemiological studies of dysplastic naevi.

Our results indicate that there are two major histological forms of melanocytic atypia and that the two do not always coexist. Architectural atypia may be present alone or in association with cytological atypia, but cytological atypia in this series was not seen without architectural atypia. Most published studies to date have concentrated on the biological importance of naevi showing both architectural and

Table 2 Clinical histories of eight patients with naevi showing architectural atypia but no cytological atypia

\begin{tabular}{lllll}
\hline No of patients & $\begin{array}{l}\text { Presence of clinically } \\
\text { atypical naevi* }\end{array}$ & $\begin{array}{l}\text { Personal history of } \\
\text { malignant melanoma }\end{array}$ & $\begin{array}{l}\text { Family history of } \\
\text { clinically atypical naevi* }\end{array}$ & $\begin{array}{l}\text { Family history of } \\
\text { malignant melanoma }\end{array}$ \\
\hline 1 & No & No & No & No \\
4 & Yes & No & No & No \\
1 & Yes & No & Yes & No \\
2 & Yes & Yes & No & No \\
\hline
\end{tabular}

*Clinical atypia in this study is defined as (1) greater than $7 \mathrm{~mm}$ in maximum diameter; (2) an irregular lateral edge; (3) irregular pigmentation within the lesion and between adjacent lesions; and (4) an apparent inflammatory flare. 


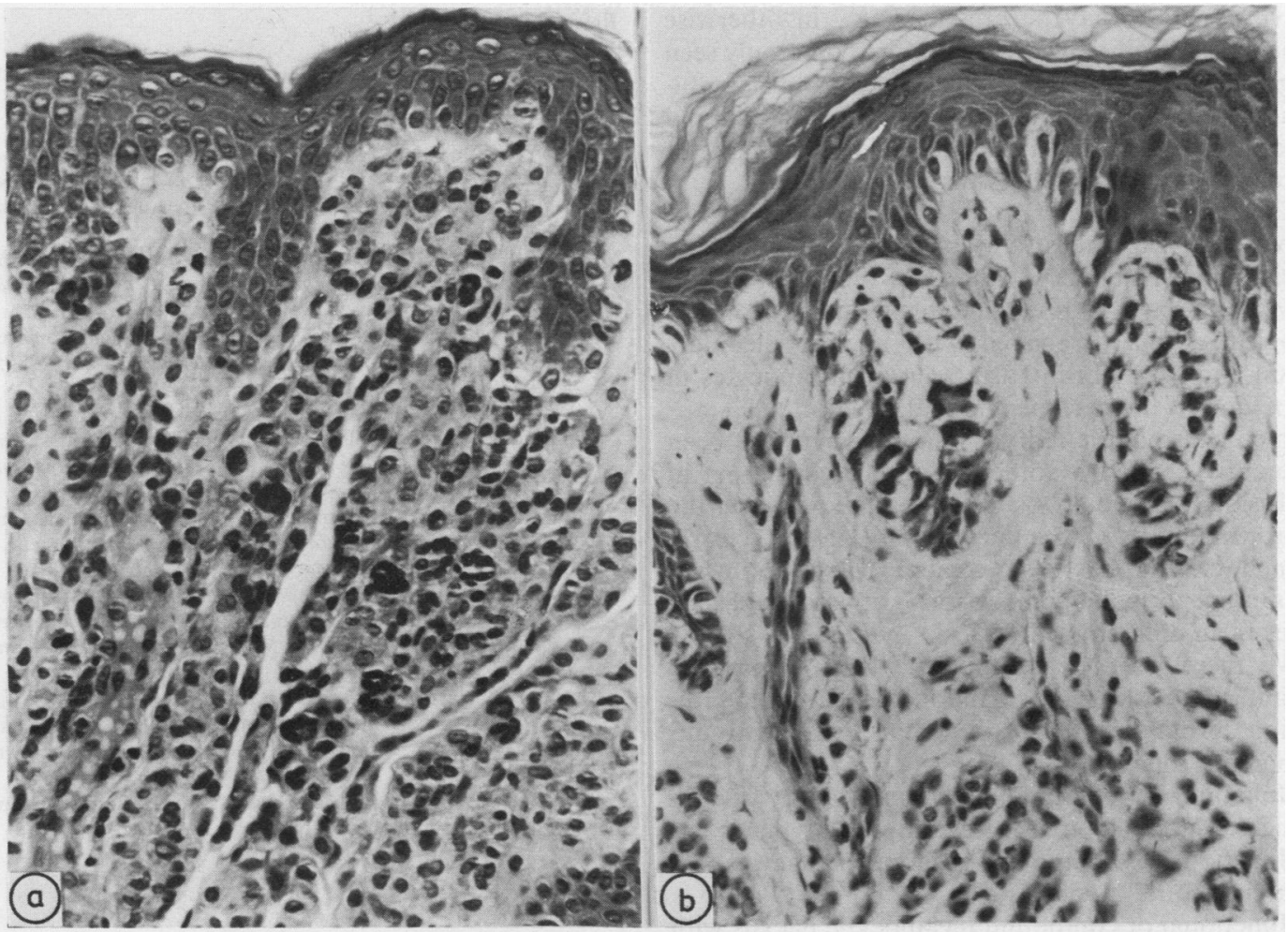

Fig. 6 (a) Banal giant cell formation in an otherwise "normal" melanocytic naevus. Note that multinucleate cells are in dermal component of naevus. (b) Multinucleate giant cell formation in junctional theque of melanocytes. Naevus shows both architectural and cytological atypia.

cytological atypia. It has been suggested that such naevi are cutaneous markers of patients who are at increased risk of developing malignant melanoma, ${ }^{167}$ and, furthermore, that these naevi are the actual histogenetic precursors of some malignant melanomas. This is based primarily on histological evidence of melanocytic dysplasia contiguous with a proportion of melanomas. ${ }^{1289}$

No study to date has reported on the behaviour of naevi showing only architectural atypia, and it cannot currently be assumed that these are the precursors of malignant melanoma. Until it is established whether or not naevi initially showing only architectural atypia progress in time to show additional cytological atypia, we consider it essential to separate these two categories of histological atypia in pathology reports and publications.

The biological importance of a dermal host response in melanocytic naevi is of interest. It is clear from our results that neither a lymphocytic response nor dermal fibroplasia occurring in isolation can be regarded as a specific feature of histologically atypical

Table 3 Clinical histories of eighteen patients who had thirty naevi removed showing both architectural and cytological atypia

\begin{tabular}{lllll}
\hline No of patients & $\begin{array}{l}\text { Presence of clinically } \\
\text { atypical naevi }\end{array}$ & $\begin{array}{l}\text { Personal history of } \\
\text { malignant melanoma }\end{array}$ & $\begin{array}{l}\text { Family history of } \\
\text { clinically atypical naevi }\end{array}$ & $\begin{array}{l}\text { Family history of } \\
\text { malignant melanoma }\end{array}$ \\
\hline 8 & + & - & - & - \\
2 & + & - & + & - \\
4 & + & + & + & - \\
2 & + & + & + & + \\
1 & + & + & + & + \\
1 & & & + & + \\
\hline
\end{tabular}


naevi, as either may be present singly in otherwise banal naevi. Both, however, are more commonly seen singly in association with atypical naevi, and a combination of both a lymphoid response and dermal fibroplasia is seen most often in naevi both with architectural and cytological atypia.

The importance, if any, of increased numbers of naevus type giant cells in atypical naevi is not clear. Their importance in the context of this study is that they should be recognised and distinguished from cytological atypia associated with nuclear pleomorphism and hyperchromatism seen in melanocytes in the region of the dermoepidermal junction.

In conclusion, the term dysplastic naevus has been differently defined by different authors, resulting in confusion for the diagnostic histopathologist over the appropriate use of the term. This lack of clearly defined criteria has also created difficulties when attempting to make comparisons between published series from different centres.

We therefore propose that the term "dysplastic melanocytic naevus" be abandoned and that the following terminology be adopted as clear and unambiguous alternatives:

1 Junctional or compound melanocytic naevus with neither architectural nor cytological atypia.

2 Junctional or compound melanocytic naevus with architectural atypia.

3 Junctional or compound melanocytic naevus with both architectural and cytological atypia.

In each of these three categories, the presence of a lymphocytic infiltrate, fibroplasia, and naevus type giant cells should also be recorded.

\section{References}

${ }^{1}$ Elder DE, Goldman LI, Goldman SC, Greene MH, Clark WH. Dysplastic naevus syndrome. A phenotypic association of sporadic cutaneous melanoma. Cancer 1980;46:1787-94.

${ }^{2}$ Clark WH, Elder DE, Guerry D, Epstein MN, Greene MH, Van Horn M. A study of tumour progression: the precursor lesions of superficial spreading and nodular melanoma. Hum Pathol 1984;15:1147-65.

${ }^{3}$ Elder DE, Greene MH, Kraemer KH, Clark WH. The dysplastic naevus syndrome. Our definition. Am J Dermatopathol 1982;4:455-60.

4 National Institutes of Health Consensus Development Conference, 1984. Precursors to malignant melanoma. JAMA 1984;251: $1864-6$.

${ }^{5}$ Ackerman AB, Minara I. Dysplasia, dysplastic melanocytes, dysplastic naevi, the dysplastic naevus syndrome and the relation between dysplastic naevi and malignant melanomas Hum Pathol 1985;16:87-91.

${ }^{6}$ Reimer RR, Clark WH, Greene MH, Ainsworth AM, Fraumeni JF. Precursor lesions in familial melanoma. A new genetic preneoplastic syndrome. JAMA 1978;239:744-6.

${ }^{7}$ Clark WH, Reimer RR, Greene MH, Ainsworth AM, Mastrangelo MJ. Origin of familial malignant melanomas from heritable melanocytic lesions. (The B-K Mole Syndrome). Arch Dermatol 1978;114:732-8.

${ }^{8}$ Rhodes AR, Harrist TJ, Day CL, Mihm MC, Fitzpatrick TB, Sober AJ. Dysplastic melanocytic nevi in histologic association with 234 primary cutaneous melanomas. J Am Acad Dermatol 1983;9:563-74.

${ }^{9}$ Cook MG, Robertson I. Melanocytic dysplasia and melanoma. Histopathology 1985;9:647-58.

Requests for reprints to: Professor Rona MacKic. Department of Dermatology, Anderson College Building. 56 Dumbarton Road, Glasgow G11 6NU, Scotland. 